\title{
Análise comparada da descentralização do licenciamento ambiental em municípios dos estados de Minas Gerais e Piauí
}

\author{
Comparative analysis of environmental licensing \\ decentralization in municipalities of the brazilian states \\ of Minas Gerais and Piauí
}

Emanoele Lima Abreu ${ }^{a}$ Alberto Fonseca ${ }^{b}$

${ }^{a}$ Mestre em Engenharia Ambiental, Universidade Federal de Ouro Preto, Ouro Preto, MG, Brasil. End. Eletrônico: emanoelelimaabreu@gmail.com

${ }^{\circ}$ Professor e pesquisador da Universidade Federal de Ouro Preto, Ouro Preto, MG, Brasil. End. Eletrônico: albertof@em.ufop.br

doi:10.18472/SustDeb.v8n3.2017.21891

Recebido em 26.12.2016

Aceito em 23.08.2017

ARTIGO - VARIA

\section{RESUMO}

Apesar do crescente interesse pela municipalização do licenciamento ambiental, poucos estudos científicos com revisão de pares foram publicados sobre esse fenômeno, sobretudo no Nordeste. 0 objetivo deste trabalho foi avaliar comparativamente experiências de municipalização do licenciamento ambiental em dois municípios no estado do Piauí (Teresina e Água Branca) e dois municípios no estado de Minas Gerais (Belo Horizonte e Betim). Utilizou-se uma abordagem metodológica qualitativa de estudo de casos múltiplos, com dados coletados por meio de análises documentais e de entrevistas estruturadas com representantes de prefeituras. Foram identificadas diferenças significativas, por exemplo, de capacidade institucional e arranjos regulatórios, entre os estados e cidades pesquisados. A qualidade do sistema de licenciamento ambiental nos municípios pode estar relacionada ao porte da administração municipal e às condições socioeconômicas locais, mas estudos adicionais são necessários para confirmar tal situação. De maneira geral, os entrevistados corroboram estudos anteriores que salientam barreiras de recursos humanos e de infraestrutura para a eficiência do licenciamento ambiental local. $\mathrm{O}$ artigo conclui com sugestões de estudos futuros.

Palavras-chave: Licenciamento Ambiental. Municipalização. Avaliação de Impacto. Política Ambiental. Minas Gerais. Piauí.

\section{ABSTRACT}

There has been a growing interest in the decentralization of environmental licensing in Brazil. However, few peer-review scholarly studies have evaluated this phenomenon, particularly in the northeastern region. The objective of this paper was to undertake a comparative analysis of the decentralization of environmental licensing in two municipalities in the State of Piauí (Teresina and Água Branca) and two municipalities in the state of Minas Gerais (Belo Horizonte and Betim). The study adopted a qualitative 
methodological approach based on multiple case studies analysis. Data were collected from content analysis and structured interviews. The study found significant institutional and regulatory differences among the state and municipalities. The quality of the municipal environmental licensing system is seemingly related to administration size and local socioeconomic conditions, but further studies are needed to confirm this finding. The interviewees' perceptions corroborate previous studies that identified lack of human resources and infrastructure as key barriers to environmental licensing at the municipal level. The study concludes with suggestions for future research avenues.

Keywords: Environmental Licensing; Decentralization; Impact Assessment; Environmental Policy; Minas Gerais; Piauí; Brazil.

\section{INTRODUÇÃO}

O licenciamento ambiental é um processo administrativo que tem como principal objetivo a defesa do meio ambiente e da qualidade de vida por meio do controle prévio de atividades efetiva e potencialmente poluidoras. Antes de ser incluído entre os principais instrumentos da política nacional do meio ambiente, por meio da Lei Federal no 6938 de 1981, o licenciamento ambiental já havia sido regulado em alguns estados. Por exemplo, no final da década de 1970, os estados do Rio de Janeiro e São Paulo já determinavam a obrigatoriedade da emissão de licença ambiental, embora limitada a algumas atividades industriais e projetos urbanísticos (SÁNCHEZ, 2013).

Em 1986, a Resolução Conama no 001 fortaleceu o vínculo do licenciamento ambiental com a Avaliação de Impacto Ambiental (AIA) ao determinar a obrigatoriedade de elaboração de estudo de impacto ambiental para o licenciamento de atividades modificadoras do meio ambiente. Com a Constituição Federal de 1988, a proteção ambiental passou a ser um direito social, reforçando a obrigatoriedade de apresentação de estudos prévios de impacto ambiental. Posteriormente, a Resolução Conama no 237/1997 estabeleceu competências e regras para o licenciamento ambiental. Mais recentemente, a Lei Complementar no 140/2011 regulamentou o artigo 23 da CF/1988 e fixou normas para a cooperação entre a União, Estados, Distrito Federal e municípios nas ações de competência comum, entre elas o licenciamento ambiental. Para Guerra (2012), essa lei definiu e reforçou a competência dos órgãos ambientais, trazendo certa segurança jurídica aos funcionários dos órgãos licenciadores, e aprimorou a harmonização do licenciamento ao disciplinar as ações de cooperação administrativa entre os entes federativos brasileiros.

Como recentemente observaram Fonseca e Resende (2016), apesar da falta de estatísticas consolidadas, os dados dos diversos órgãos ambientais brasileiros sugerem que, anualmente, sejam emitidas dezenas de milhares de licenças ambientais no Brasil. Historicamente, a imensa maioria dessas licenças tem sido emitida por órgãos estaduais. Todavia, o licenciamento ambiental municipal tem crescido. Segundo o Instituto Brasileiro de Geografia e Estatística - IBGE (2016), 30,4\% dos municípios brasileiros realizavam algum tipo de licenciamento ambiental em 2015.

Apesar do seu crescente uso e regulação, o licenciamento ambiental tem sido acusado de ineficiente, burocrático e moroso por muitos autores e instituições (FONSECA; SÁNCHEZ; RIBEIRO, 2016). Para tentar aliviar a burocracia, entre outros sintomas de ineficiência do licenciamento, os estados têm incentivado seus municípios a assumirem o licenciamento de atividades e empreendimentos de impacto de abrangência local.

Como observou Farias (2014), a tendência de descentralização do licenciamento ambiental está profundamente embasada no princípio da subsidiariedade (do inglês subsidiarity), que determina que as decisões e ações do Estado devam acontecer nos níveis mais baixos do sistema político, a não ser que sua eficiência seja maior nos níveis mais altos (FOLESDALI, 1998). Esse princípio é, há muito, destacado como essencial nos processos de descentralização da gestão ambiental (RIBOT, 2002).

Os benefícios da descentralização do licenciamento ambiental vão além da suposta eficiência na emissão das licenças; espera-se que a proximidade da população e do poder público local facilite o controle dos impactos ambientais gerados pelas atividades e empreendimentos licenciados. No entanto, 
a capacidade dos municípios ainda é questionada devido às diversas barreiras financeiras, políticas e institucionais. Como Marshall (2008) observa, frequentemente ocorre uma situação paradoxal na construção de condições adequadas para a descentralização da gestão ambiental: (...) "há geralmente uma relutância em descentralizar tarefas para entes mais baixos antes que sua capacidade tenha sido provada, mas é impossível estabelecer essa prova até a existência dessas condições [descentralização]" (p. 82).

As condições do licenciamento ambiental municipal restam superficialmente exploradas na academia brasileira. Apesar de existirem muitos trabalhos sobre a municipalização disponíveis na Internet, apenas uma parcela desses estudos passou por revisão de pares e foi publicada em periódicos científicos de maior circulação. Alguns estudos descreveram, por meio de análises de casos, como vem ocorrendo o processo de municipalização em alguns municípios, destacando, por exemplo, os mecanismos de cooperação utilizados nos seus respectivos estados, como foi descrito no Espírito Santo por Chiesa (2009) e no Pará por Correa (2011).

Porém, diante do crescimento e diversificação da municipalização, ainda restam questões desconhecidas sobre esse fenômeno, como, por exemplo, as variações geográficas e suas potenciais influências sobre a efetividade do licenciamento ambiental. Uma das exceções foi o estudo de Souza (2003) que descreveu o processo de descentralização nos estados da Bahia, Minas Gerais e Rio Grande do Sul. Todavia, o autor fez uma análise mais "macro", sem captar as experiências específicas de municípios dos respectivos estados. Além disso, muitos desses estudos se basearam em análises de legislação, técnica de coleta de dados que não revela detalhadamente os efeitos práticos desse instrumento de política ambiental.

Nesse contexto, o presente trabalho objetivou analisar comparativamente experiências de municipalização do licenciamento ambiental em municípios dos estados do Piauí e de Minas. Para tanto, foram selecionadas suas capitais, respectivamente, Belo Horizonte e Teresina, e duas cidades interioranas, Betim e Água Branca. Foi analisada a percepção dos servidores lotados nas Secretarias Municipais de Meio Ambiente dos respectivos municípios quanto à eficiência, pontos fortes e fracos do sistema e recomendações às prefeituras que estejam nesse processo. As pluralidades de experiências captadas nesta pesquisa, apesar de tratar diretamente de dois estados, podem interessar gestores e pesquisadores de diversas regiões geográficas, não apenas no Brasil, mas também onde a temática da descentralização da política ambiental seja relevante.

\section{METODOLOGIA}

Esta pesquisa utilizou uma abordagem qualitativa de descrição de estudos de casos múltiplos, que, de acordo com Creswell (2010), é apropriada para entender fenômenos sociais que ainda não tenham sido muito pesquisados. Para a coleta de dados, foram realizadas a) revisão e síntese de literatura; b) análise de conteúdo da legislação estadual e municipal; e c) entrevistas estruturadas com servidores públicos atuantes nos setores de licenciamento ambiental dos quatro municípios pesquisados.

Para auxiliar na caracterização do licenciamento ambiental nos municípios, que de maneira geral possuíam poucos dados secundários disponíveis ao público, foi elaborado e enviado, via e-mail, aos representantes dos órgãos ambientais dos municípios, um questionário de caracterização do licenciamento ambiental contendo 25 questões (entre abertas e fechadas), tratando de aspectos legais/regulatórios, institucionais e procedimentais. Os questionários foram respondidos por quatro representantes de prefeitura, sendo um de cada município.

Para entender as experiências de municipalização a partir daqueles que mais diretamente trabalham no controle do licenciamento municipal, ou seja, gestores públicos, foram contatados funcionários/ empregados dos órgãos licenciadores dos quatro municípios estudados para responder a um Questionário de Percepção. Tal questionário apresentava quatro questões, sendo uma fechada e três abertas indagando os atores envolvidos quanto à eficiência, pontos fortes e fracos do processo de licenciamento ambiental no município, bem como quanto às eventuais recomendações para aprimoramento do licenciamento. Conforme sintetiza o Quadro 1, foram retornados quatro 
questionários de Teresina, quatro de Belo Horizonte, três de Betim e um de Água Branca, totalizando 12 questionários.

Quadro 1 - Perfil dos entrevistados e quantidade de entrevistas sobre a percepção do sistema municipal de licenciamento ambiental nos estados de Minas Gerais e Piauí.

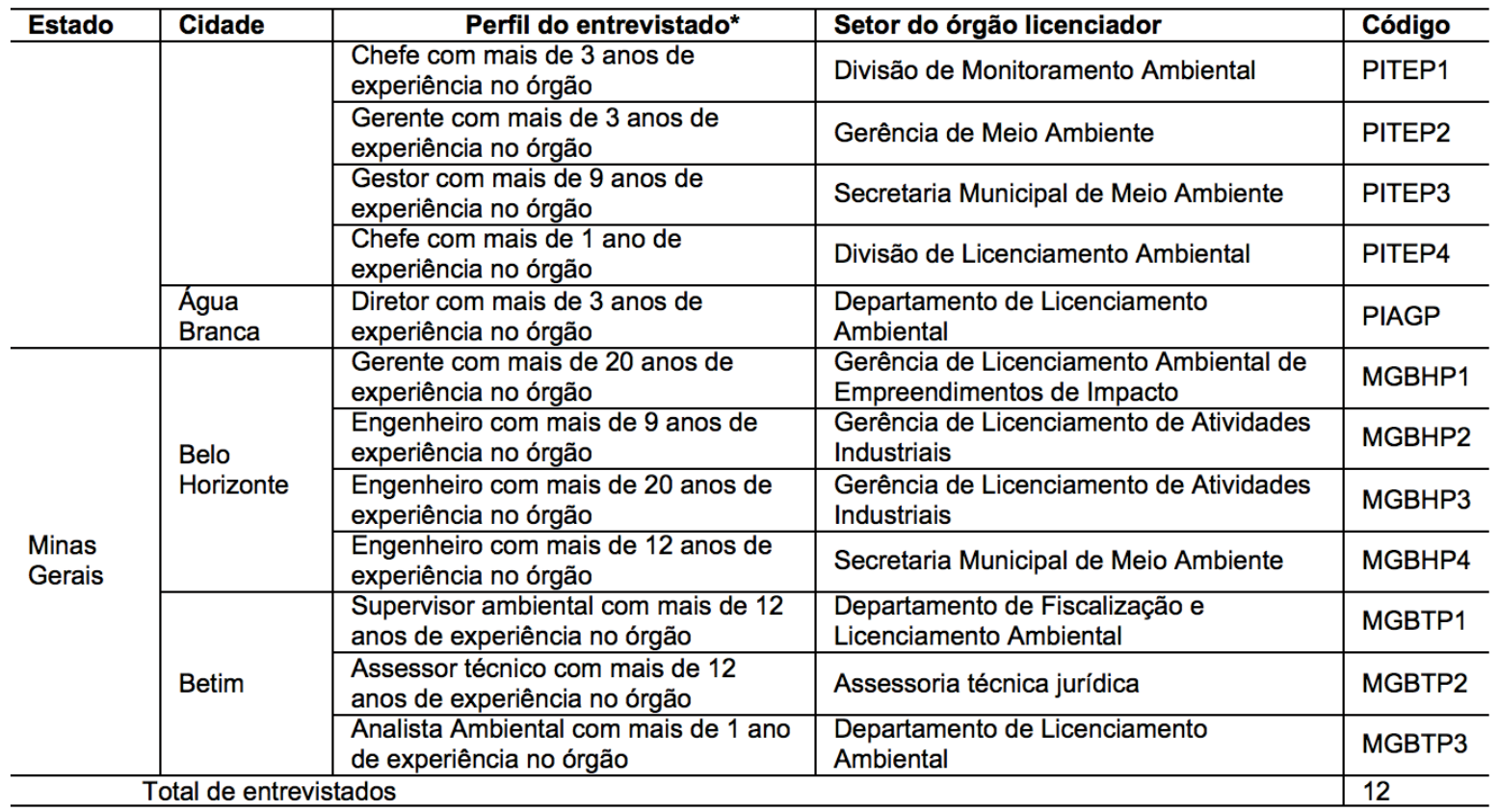

* Os entrevistados incluíam representantes do gênero masculino e feminino, mas, para assegurar o anonimato, os entrevistados foram tratados nesta pesquisa genericamente, sem identificação de gênero.

Fonte: Elaborado pelos autores.

Esta pesquisa não teve a pretensão de coletar uma amostra estatisticamente significativa de entrevistados, mas, tão somente, de capturar a percepção daqueles que estavam bem informados sobre as rotinas do licenciamento ambiental no município. A amostra tentou capturar contextos geográficos, institucionais e populacionais distintos. Nesse sentido, foram incluídos na amostra municípios do Sudeste e do Nordeste, bem como municípios com níveis elevados e baixos de industrialização, com populações municipais variando de 17 mil habitantes a 2,5 milhões de habitantes. Os questionários foram enviados por e-mail a representantes das Secretarias de Meio Ambiente. Também foram realizadas ligações telefônicas para as Secretarias de Meio Ambiente dos municípios, de modo a relembrar a importância da pesquisa e sensibilizar representantes experientes das prefeituras a retornarem os questionários plenamente preenchidos. O número baixo de devolução de questionários em Água Branca (1) espelha o número reduzido de servidores da pasta ambiental do município, conforme se lerá na seção seguinte. Como não se sabe exatamente o quantitativo e perfil de todos os empregados das Secretarias de Meio Ambiente, não foi possível avaliar quão significativas ou não foram as taxas de resposta.

\section{RESULTADOS}

\subsection{CARACTERIZAÇÃO DA MUNICIPALIZAÇÃO DO LICENCIAMENTO AMBIENTAL NOS ESTADOS DE MINAS GERAIS E PIAUÍ}

Os questionários aplicados foram divididos em três dimensões: legal/regulatória, que trata dos principais mecanismos de regulação ambiental nos municípios; institucional, que trata de informações básicas sobre as Secretarias Municipais de Meio Ambiente; e procedimental, que trata do rito administrativo do processo de licenciamento. Por se tratar de um grande volume de dados obtidos por meio dos questionários, optou-se por apresentar, no Quadro 2, uma síntese dos resultados de cada dimensão. 
Quadro 2 - Síntese dos aspectos regulatórios, institucionais e procedimentais do licenciamento municipal nos estados de Minas Gerais e Piauí.

\begin{tabular}{|c|c|c|c|c|}
\hline \multirow{2}{*}{ Aspectos Analisados } & \multicolumn{2}{|c|}{ Minas Gerais } & \multicolumn{2}{|c|}{ Piauí } \\
\hline & Belo Horizonte & Betim & Teresina & Agua Branca \\
\hline \multicolumn{5}{|l|}{ Dados Censitários* } \\
\hline $\begin{array}{l}\text { População estimada } \\
(2015)\end{array}$ & 2.502 .557 & 417.307 & 844.245 & 17.010 \\
\hline $\begin{array}{l}\text { Área do município } \\
\left(\mathrm{km}^{2}\right)\end{array}$ & 331,401 & 343,856 & 1391,981 & 97,041 \\
\hline $\begin{array}{l}\text { PIB per capita (R\$, } \\
2013)\end{array}$ & $32.844,41$ & $55.338,50$ & $17.697,64$ & $7.325,79$ \\
\hline $\begin{array}{l}\text { IDH - } 2010 \text { (IDHM } \\
2010)\end{array}$ & 0,810 (muito alto) & 0,749 (alto) & 0,751 (alto) & 0,639 (médio) \\
\hline \multicolumn{5}{|c|}{ Dimensăo Regulatória } \\
\hline $\begin{array}{l}\text { Principal legislação } \\
\text { municipal sobre } \\
\text { licenciamento } \\
\text { ambiental }\end{array}$ & $\begin{array}{l}\text { Leis Municipais } n^{\circ} \\
4.253 / 1985 \text { e } 7.277 / 1997 \text {; } \\
\text { Deliberação Normativa } \\
\text { Comam }{ }^{\star \star} n^{\circ} 42 / 02 \mathrm{e} \\
\text { outras. }\end{array}$ & $\begin{array}{l}\text { Leis Municipais } n^{\circ} \\
3.274 / 1999 \\
3.650 / 2002 \text { e } \\
5.628 / 2013 ; \text { Decretos } \\
\text { Municipais } \\
\text { 16.660/2001 e } \\
\text { 18.638/0; Resoluções } \\
\text { Codema** } 01 / 14 \text { e } \\
01 / 15\end{array}$ & $\begin{array}{l}\text { Lei Municipal } \\
2.475 / 1996 .\end{array}$ & $\begin{array}{l}\text { Lei Municipal } \\
421 / 2012 \text {. }\end{array}$ \\
\hline $\begin{array}{l}\text { Assinou convênio ou } \\
\text { acordo com o Estado? }\end{array}$ & $\begin{array}{l}\text { Sim (Deliberação } \\
\text { Normativa Copam** } \\
\text { 102/2006) }\end{array}$ & $\begin{array}{l}\text { Sim (assinado em } \\
20 / 03 / 2013 \text { ) }\end{array}$ & $\begin{array}{l}\text { Nảo foi identificado } \\
\text { acordo nem } \\
\text { convênio "formal" }\end{array}$ & $\begin{array}{l}\text { Sim (Resolução } \\
\text { Consema }^{* \star} \\
\text { 015/2010) } \\
\end{array}$ \\
\hline Possui Plano Diretor? & $\begin{array}{l}\text { Sim (Lei Municipal } n^{\circ} \\
7.165 / 1996)\end{array}$ & $\begin{array}{l}\text { Sim (Lei Municipal } n^{\circ} \\
4.574 / 2007)\end{array}$ & $\begin{array}{l}\text { Sim (mas nảo foi } \\
\text { identificada lei } \\
\text { especifica) }\end{array}$ & $\begin{array}{l}\text { Sim (Lei Municipal } \\
\left.n^{\circ} 415 / 2011\right)\end{array}$ \\
\hline $\begin{array}{l}\text { Possui Lei de Uso e } \\
\text { Ocupação do Solo? }\end{array}$ & Sim (diversas leis) & $\begin{array}{l}\text { Sim (Lei Municipal } \\
5.386 / 2012 \text { ) }\end{array}$ & $\begin{array}{l}\text { Sim (Lei Municipal } \\
3.560 / 2006)\end{array}$ & $\begin{array}{l}\text { Sim (Lei Municipal } \\
233 / 97 \text { ) }\end{array}$ \\
\hline $\begin{array}{l}\text { Possui Fundo } \\
\text { Municipal de Meio } \\
\text { Ambiente? }\end{array}$ & $\begin{array}{l}\text { Sim (Lei Municipal } \\
4.253 / 1985 \text { e DN Coman } \\
78 / 13 \text { ) }\end{array}$ & $\begin{array}{l}\text { Sim (Lei Municipal } \\
3.274 / 1999)\end{array}$ & $\begin{array}{l}\text { Sim (Lei Municipal } \\
2.476 / 1996)\end{array}$ & $\begin{array}{l}\text { Sim (Lei Municipal } \\
292 / 2003 \text { ) }\end{array}$ \\
\hline \multicolumn{5}{|c|}{ Dimensăo Institucional } \\
\hline $\begin{array}{l}\text { Principal instituição } \\
\text { licenciadora no } \\
\text { município }\end{array}$ & $\begin{array}{l}\text { Secretaria Municipal de } \\
\text { Meio Ambiente (SMMA) }\end{array}$ & $\begin{array}{l}\text { Secretaria Municipal } \\
\text { de Meio Ambiente e } \\
\text { Desenvolvimento } \\
\text { Sustentável } \\
\text { (SEMMAD) }\end{array}$ & $\begin{array}{l}\text { Secretaria } \\
\text { Municipal de Meio } \\
\text { Ambiente e } \\
\text { Recursos Hídricos } \\
\text { (Semam) } \\
\end{array}$ & $\begin{array}{l}\text { Secretaria } \\
\text { Municipal de Meio } \\
\text { Ambiente (Semam) }\end{array}$ \\
\hline $\begin{array}{l}\text { Natureza da instituição } \\
\text { licenciadora }\end{array}$ & $\begin{array}{l}\text { Orgão Público do Poder } \\
\text { Executivo Municipal }\end{array}$ & $\begin{array}{l}\text { Orgăo Público do } \\
\text { Poder Executivo } \\
\text { Municipal }\end{array}$ & $\begin{array}{l}\text { Orgão Público do } \\
\text { Poder Executivo } \\
\text { Municipal }\end{array}$ & $\begin{array}{l}\text { Orgåo Público do } \\
\text { Poder Executivo } \\
\text { Municipal }\end{array}$ \\
\hline $\begin{array}{l}\text { Número de } \\
\text { empregados (efetivos, } \\
\text { temporários e } \\
\text { concursados) atuando } \\
\text { no setor de } \\
\text { licenciamento } \\
\text { ambiental municipal. }\end{array}$ & 62 (incluindo 46 técnicos) & 15 & $\begin{array}{l}22 \text { ( } 17 \\
\text { comissionados, } 2 \\
\text { terceirizados e } 3 \\
\text { estatutários) }\end{array}$ & 3 (comissionados) \\
\hline $\begin{array}{l}\text { Contrataçăo de } \\
\text { empregados } \\
\text { terceirizados para } \\
\text { atuar no } \\
\text { licenciamento? }\end{array}$ & Não & Não & $\begin{array}{l}\text { Sim (não há } \\
\text { concursado) }\end{array}$ & $\begin{array}{l}\text { Sim (não há } \\
\text { concursado) }\end{array}$ \\
\hline $\begin{array}{l}\text { Estimativa do salário } \\
\text { mensal bruto da } \\
\text { equipe técnica do } \\
\text { licenciamento } \\
\text { ambiental (em mês } \\
\text { que não incide férias e } \\
13^{\circ} \text { ) }\end{array}$ & $\begin{array}{l}\text { Informação não } \\
\text { disponibilizada pelo } \\
\text { entrevistado nem } \\
\text { encontrada nos websites } \\
\text { da prefeitura de Belo } \\
\text { Horizonte. }\end{array}$ & $\begin{array}{l}\text { De R\$ } 1.800,00 \text { a R\$ } \\
6.000,00\end{array}$ & $\begin{array}{l}\text { De R\$ } 800,00 \text { a } \\
\mathrm{R} \$ 2.000,00 .\end{array}$ & $\begin{array}{l}\text { De R\$ } 1.300,00 \text { a } \\
\text { R\$ } 2.600,00 .\end{array}$ \\
\hline $\begin{array}{l}\text { Formações } \\
\text { profissionais presentes } \\
\text { da equipe. }\end{array}$ & $\begin{array}{l}\text { Administrador, agrimensor, } \\
\text { arquitetos, engenheiros } \\
\text { (sanitarista, eletricista, } \\
\text { ambiental, agrimensor, } \\
\text { químico), biólogo, químico } \\
\text { e sociólogo }\end{array}$ & $\begin{array}{l}\text { Engenheiros } \\
\text { (ambiental, } \\
\text { agronômico, } \\
\text { agrimensor, civil, } \\
\text { florestal e químico), } \\
\text { biólogos, arquiteto e } \\
\text { urbanista, químico, } \\
\text { técnicos diversos }\end{array}$ & $\begin{array}{l}\text { Engenheiros (civil } \\
\text { e agronômico), } \\
\text { biólogo, } \\
\text { tecnólogos, } \\
\text { médico veterinário, } \\
\text { letras, etc. }\end{array}$ & $\begin{array}{l}\text { Biólogo e } \\
\text { Engenheiros } \\
\text { (agronômico e civil) }\end{array}$ \\
\hline \multicolumn{5}{|c|}{ Dimensão Procedimental } \\
\hline $\begin{array}{l}\text { Especificação de } \\
\text { tipologias de } \\
\text { atividades e } \\
\text { empreendimentos }\end{array}$ & $\begin{array}{l}\text { Lei Municipal } n^{\circ} 7.166 / 96 \mathrm{e} \\
\text { todas as classes previstas } \\
\text { na Deliberação Normativa } \\
(\mathrm{DN}) \mathrm{n}^{\circ} 74 \text { Copam. }\end{array}$ & $\begin{array}{l}\text { Sim. Até a classe } 4 \text { da } \\
\text { DN Copam n 74/2004; } \\
\text { DN Codema n } \\
01 / 2014 .\end{array}$ & $\begin{array}{l}\text { Sim (listagem do } \\
\text { órgão estadual da } \\
\text { Resolução } \\
\text { Consema }\end{array}$ & $\begin{array}{l}\text { Sim (listagem do } \\
\text { órgão estadual da } \\
\text { Resolução } \\
\text { Consema 23/2014). }\end{array}$ \\
\hline
\end{tabular}




\begin{tabular}{|c|c|c|c|c|}
\hline $\begin{array}{l}\text { sujeitos a } \\
\text { licenciamento? }\end{array}$ & & & $23 / 2014)$ & \\
\hline $\begin{array}{l}\text { Disponibilização de } \\
\text { TRs para estudos } \\
\text { ambientais? }\end{array}$ & $\begin{array}{l}\text { Sim (seguem padrões } \\
\text { próprios do município) }\end{array}$ & $\begin{array}{l}\text { Sim (seguem padrões } \\
\text { próprios do município). }\end{array}$ & $\begin{array}{l}\text { Apenas para } \\
\text { tipologia Posto de } \\
\text { Gasolina }\end{array}$ & $\begin{array}{l}\text { Sim (seguem } \\
\text { padrões próprios } \\
\text { do estado do } \\
\text { Piauí). }\end{array}$ \\
\hline $\begin{array}{l}\text { Tipos de estudos que } \\
\text { podem ser exigidos? }\end{array}$ & $\begin{array}{l}\text { Estudo de Impacto } \\
\text { Ambiental e respectivo } \\
\text { Relatório de Impacto } \\
\text { Ambiental (EIA/Rima), } \\
\text { Plano de Controle } \\
\text { Ambiental (PCA), Relatório } \\
\text { de Controle Ambiental } \\
\text { (RCA), Relatório de } \\
\text { Avaliação de Desempenho } \\
\text { Ambiental (Rada), Plano de } \\
\text { Recuperação de Área } \\
\text { Degradada (Prad) }\end{array}$ & $\begin{array}{l}\text { EIA/Rima, PCA/PCA; } \\
\text { Prad, PCA simplificado }\end{array}$ & $\begin{array}{l}\text { PCA, PGRS, } \\
\text { Relatório } \\
\text { Ambiental } \\
\text { Simplificado } \\
\text { (RAS), EIA/Rima, } \\
\text { PRAD }\end{array}$ & PCA, PGRS, RAS \\
\hline $\begin{array}{l}\text { Análise } \\
\text { multidisciplinar? }\end{array}$ & Sim, para todas as classes & $\begin{array}{l}\text { Sim, para classes } 3 \mathrm{e} \\
4 \text {. }\end{array}$ & Não & Não \\
\hline Análise jurídica? & Sim & Sim & Sim & Não \\
\hline $\begin{array}{l}\text { Quem assina a } \\
\text { licença? }\end{array}$ & $\begin{array}{l}\text { Secretário Municipal e } \\
\text { Gerente do Licenciamento } \\
\text { Ambiental }\end{array}$ & Secretário Municipal & $\begin{array}{l}\text { Gerente da zona } \\
\text { municipal } \\
\text { conjuntamente } \\
\text { com o Secretário } \\
\text { de Meio Ambiente } \\
\text { Municipal }\end{array}$ & $\begin{array}{l}\text { Secretário } \\
\text { municipal } \\
\text { conjuntamente com } \\
\text { o Chefe do } \\
\text { Departamento de } \\
\text { Licenciamento }\end{array}$ \\
\hline $\begin{array}{l}\text { Modalidades mais } \\
\text { frequentes de licença } \\
\text { ambiental emitidas no } \\
\text { município? }\end{array}$ & $\begin{array}{l}\text { Licença Prévia (LP), } \\
\text { Licença de Instalação (LI), } \\
\text { Licença de Operação (LO), } \\
\text { Licença corretiva, licença } \\
\text { simplificada, licença de } \\
\text { adequação. }\end{array}$ & $\begin{array}{l}\text { LP, LI, LO, Licença } \\
\text { corretiva, Licença } \\
\text { simplificada e } \\
\text { autorizações } \\
\text { ambientais }\end{array}$ & $\begin{array}{l}\text { LP, LI, LO, Licença } \\
\text { corretiva e } \\
\text { autorizações } \\
\text { ambientais. }\end{array}$ & $\begin{array}{l}\text { LP, LI, LO e } \\
\text { Licença Única }\end{array}$ \\
\hline $\begin{array}{l}\text { Quem participa da } \\
\text { decisão sobre o } \\
\text { deferimento ou não da } \\
\text { licença ambiental? }\end{array}$ & $\begin{array}{l}\text { Técnicos da secretaria e, } \\
\text { dependendo da classe, } \\
\text { conselho municipal }\end{array}$ & $\begin{array}{l}\text { Técnicos da secretaria } \\
\text { e, dependendo da } \\
\text { classe, conselho } \\
\text { municipal }\end{array}$ & $\begin{array}{l}\text { Técnicos da } \\
\text { secretaria e, em } \\
\text { alguns processos, } \\
\text { ministério público }\end{array}$ & $\begin{array}{l}\text { Técnicos da } \\
\text { secretaria }\end{array}$ \\
\hline $\begin{array}{l}\text { Fiscalização no } \\
\text { licenciamento } \\
\text { ambiental? }\end{array}$ & Sim & Sim & Sim & Sim \\
\hline $\begin{array}{l}\text { Quantidade de fiscais } \\
\text { suficientes para o } \\
\text { municipio? }\end{array}$ & Não & Não & Não & $\begin{array}{l}\text { Năo (na verdade, } \\
\text { nem possui fiscal } \\
\text { de meio ambiente) }\end{array}$ \\
\hline $\begin{array}{l}\text { Sistema informatizado } \\
\text { de acompanhamento } \\
\text { dos empreendimentos } \\
\text { licenciados? }\end{array}$ & Sim & Sim & Não & Não \\
\hline
\end{tabular}

Fonte: Questionários coletados na pesquisa, complementados com informações dos websites das instituições municipais.

*Baseado em IBGE (2016). **Siglas utilizadas no quadro: Conselho Estadual do Meio Ambiente do Piauí (Consema), Conselho Municipal de Desenvolvimento Ambiental de Betim (Codema), Conselho Municipal do Meio Ambiente de Belo Horizonte (Comam) e Conselho de Política Ambiental do Estado de Minas Gerais (Copam).

Os quatro municípios representam uma amostra de experiências de municipalização do licenciamento ambiental que se iniciaram antes da publicação da Lei Complementar no 140/2011. Em Belo Horizonte, o primeiro convênio assinado com o Estado foi no ano de 1985, indicando que algum tipo de licenciamento ambiental já era realizado nesse período. Já em Betim esse convênio foi assinado em 2013, porém, de acordo com o IBGE (2010), no ano de 2009 o município já realizava o licenciamento ambiental de atividades de impacto local. Em Teresina, como não há convênio com o Estado e a Semam foi desfeita duas vezes, não foram identificados dados claros durante a pesquisa sobre o início do processo de licenciamento na capital. No município de Água Branca, de acordo com informações obtidas no Questionário de Caracterização, a Semam até então apenas renovava licenças ambientais já emitidas pelo órgão estadual licenciador, que transferiu os processos para o município após habilitá-lo.

Todos os municípios apresentam exemplos de instrumentos mandatórios de política ambiental que a literatura salienta como fundamentais para a municipalização do licenciamento, tais como Plano Diretor, Conselho Municipal de Meio Ambiente, Lei de Uso e Ocupação do Solo e Fundo Municipal do Meio Ambiente. A existência desses instrumentos pode sugerir capacidades similares de institucionalização da municipalização do licenciamento ambiental. Todavia, os quatro municípios aqui pesquisados apresentaram condições muito diferenciadas de execução do licenciamento ambiental. 
Os municípios mineiros (Belo Horizonte e Betim) apresentam atributos institucionais que sugerem que os seus respectivos sistemas de licenciamento ambiental estão mais capacitados para conduzir o processo. Suas secretarias trabalham com diversos técnicos, analistas e gestores, atuando diretamente no setor de licenciamento ambiental. Água Branca, o município de menor porte pesquisado, evidenciou clara limitação de equipe técnica, que contava apenas com três funcionários comissionados, além de não possuir profissional habilitado para a análise jurídica dos processos, nem mesmo fiscais ambientais. Nas demais cidades, apesar das Secretarias de Meio Ambiente terem declarado que possuíam número de fiscais insuficiente, apresentavam pelo menos um profissional habilitado para análise jurídica dos processos e, no caso de Belo Horizonte e Betim, equipe multidisciplinar habilitada para análise técnica. Em Teresina essa função ficava a cargo apenas do gerente de Meio Ambiente que, em casos mais complexos, solicitava ajuda por parte de outros funcionários da secretaria. Não existe uma equipe própria para consulta, visto que anualmente os funcionários podem ser substituídos.

Em Betim e Belo Horizonte, os Conselhos Municipais de Meio Ambiente participam da tomada de decisão quanto ao deferimento das licenças ambientais, nos casos de empreendimentos mais complexos. Nesses dois municípios, também existem sistemas informatizados de acompanhamento dos processos de licenciamento ambiental.

\subsection{PERCEPÇÃO DOS GESTORES PÚBLICOS DOS ÓRGÃOS AMBIENTAIS}

Este trabalho, além de caracterizar o quadro institucional, regulatório e procedimental do licenciamento ambiental municipal, objetivou conhecer a percepção dos servidores que atuam diretamente com o licenciamento em seus respectivos municípios, visto que eles vivenciam diariamente os desafios e entraves do processo. Essas experiências permitiram identificar alguns dos principais obstáculos que devem ser enfrentados pelas prefeituras que almejam assumir o licenciamento no seu território. No total foram entrevistados doze (12) servidores, conforme o Quadro 1 apresentado.

\subsubsection{EFICIÊNCIA GERAL DO LICENCIAMENTO AMBIENTAL MUNICIPAL}

Conforme descrito na metodologia, os servidores foram questionados quanto à eficiência do licenciamento ambiental no município. A visão dos servidores consultados em Belo Horizonte (4 servidores) e Betim (3 servidores) é que o processo tem sido eficiente. Entretanto, em Teresina foi observada uma divergência de opinião entre os quatro servidores. Enquanto os entrevistados PITEP2 e PITEP3, respectivamente gerente e secretário adjunto, responderam que o processo tem sido eficiente, os entrevistados PITEP1 e PITEP4, ambos chefes de divisão e que, portanto, lidam diretamente com o licenciamento, consideram que o processo tem se mostrado nada ou pouco eficiente. $O$ único entrevistado de Água Branca, PIAGP, respondeu que o licenciamento ambiental é pouco eficiente no município.

Essas percepções de eficiência indicam pouco sobre as reais capacidades locais de implementar o licenciamento ambiental. Na literatura, não há, até o momento, consenso sobre como medir eficiência na implementação do licenciamento ambiental, seja no nível local ou nos níveis superiores da Federação. O conceito de "efetividade" pode ser interpretado de diferentes maneiras. Como destacou Morgan (2007), "os governos são melhores em falar sobre descentralização do que em fazer" (p. 83). Nesse contexto, deve-se ter cautela com opiniões e se pautar pelo entendimento dos fatos, à luz do contexto municipal.

\subsubsection{PONTOS FRACOS DO LICENCIAMENTO AMBIENTAL MUNICIPAL}

Na segunda questão, foram apontados pelos entrevistados os principais problemas do licenciamento ambiental no município, sendo agrupados em seis categorias: i) Número de funcionários envolvidos e capacidade técnica da equipe responsável pelo licenciamento ambiental; ii) Interferência política; iii) Burocracia e falta de engajamento institucional e planejamento; iv) Falta de estrutura física e administrativa; v) Baixa qualidade dos estudos ambientais apresentados; e vi) Legislação ambiental. 
Para sete dos dez entrevistados, o número de funcionários envolvidos e a capacidade técnica destes podem ser entraves para a realização do licenciamento ambiental. No município de Água Branca, de acordo com o entrevistado PIAGP, o quadro de funcionários é muito abaixo do mínimo adequado. Ainda de acordo com o mesmo entrevistado, a equipe se limita a um engenheiro agrônomo, uma bióloga e um engenheiro civil emprestado eventualmente pela prefeitura, o que foi descrito na caracterização do município.

O baixo número de funcionários também foi ressaltado como um problema dentro do órgão ambiental municipal de Teresina pelos entrevistados PITEP1 e PITEP2. Segundo o entrevistado PITEP2, além de existir pouco efetivo dentro do órgão, muitas vezes os servidores existentes possuem baixo conhecimento sobre a área ambiental, principalmente sobre a legislação. Esse ponto é reforçado pelo entrevistado PITEP4, que aponta a falta de treinamento e capacitação tanto para os antigos como para os novos servidores. Além disso, os entrevistados PITEP1 e PITEP3 afirmaram que há uma necessidade de corpo técnico qualificado para a análise dos processos e documentos.

A falta de recursos humanos, bem como a capacidade técnica da equipe, foi um dos principais gargalos apontados na literatura. Blazina e Lipp-Nissinem (2010) observaram que a maioria dos municípios do Rio Grande do Sul possuía de um até cinco servidores, como o caso de Roca Sales que, de acordo com Brant et al. (2013), apresentava uma equipe multidisciplinar formada por cinco funcionários, todos responsáveis por todas as etapas do licenciamento dos empreendimentos.

Em Betim, a baixa remuneração da equipe foi sinalizada como um dos motivos da alta rotatividade de funcionários dentro da secretaria (MGBTP1). Segundo o entrevistado MGBT3, em Betim, para ampliar a equipe técnica responsável pelo licenciamento ambiental, o órgão funciona por meio de mudanças frequentes de servidores comissionados, situação que, de acordo com o entrevistado MGBTP1, pode interromper os processos desenvolvidos dentro do órgão ambiental. A quebra da continuidade das ações também foi apontada em Belo Horizonte pelo entrevistado MGBHP1, que relacionou esse fenômeno ao viés político da SMMA. Para o entrevistado MGBHP4, essa vulnerabilidade política, também sinalizada pelo entrevistado MGBHP1, é um entrave encontrado na secretaria, visto que empreendimentos particulares de grande porte e públicos, de interesse do Executivo, sofrem pressão para serem licenciados.

Esses entraves estão alinhados com estudos anteriores. No município de Itaguaí, Guilherme e Henkes (2013) também observaram a evasão dos funcionários do órgão ambiental municipal devido aos baixos salários oferecidos. Em Belém, Corrêa (2011) verificou que o número de efetivos do órgão ambiental municipal diminuiu em determinado período e que grande parte dos serviços da secretaria, incluindo o departamento de licenciamento ambiental, passou a funcionar por meio do rodízio de funcionários contratados e comissionados. Isso, segundo a autora, daria abertura para que "a troca de favores e práticas clientelistas sejam critérios de seleção aos cargos". Neves (2013) constatou o mesmo nos demais municípios paraenses, que, no período estudado, também possuíam o quadro de funcionários formado, em sua maioria, por temporários e com qualificação não compatível com as necessidades dos órgãos ambientais municipais.

Além da equipe envolvida e os interesses políticos externos, outros fatores podem influenciar no fluxo dos procedimentos dentro do órgão licenciador, ocasionando o atraso da análise dos processos e tornando o licenciamento excessivamente burocrático. Para o entrevistado MGBTP1, a falta de interface entre os outros órgãos e/ou departamentos, relacionados direta ou indiretamente ao órgão ambiental municipal, é um dos principais responsáveis pela burocratização do licenciamento em Betim. Ainda sobre o mesmo município, o entrevistado MGBTP2 cita o caso dos processos que envolvem supressão vegetal em áreas de Mata Atlântica, que dependem da autorização do órgão ambiental estadual e, portanto, são mais demorados:

[...] Assim, os empreendimentos que dependem de suprimir Mata Atlântica demoram muito por causa do órgão estadual. E o município tem toda estrutura e conhecimento para analisar e exigir as compensações de Mata Atlântica. Tem advogado, engenheiro florestal, engenheiro agrônomo e biólogos (ENTREVISTADO MGBTP2). 
O entrevistado PITEP4 afirmou que além da burocracia e morosidade do processo de licenciamento na Secretaria de Meio Ambiente (Semam), a demanda é muito alta. O entrevistado PITEP1 aponta, principalmente, a demora na assinatura das licenças, que depende da apreciação de outros setores da secretaria e da análise dos estudos ambientais. Os entrevistados MGBHP1, MGBTP3 e PITEP2 apontaram que a baixa qualidade dos estudos ambientais recebidos nas secretarias, principalmente pela falta de objetividade e o excesso de informações irrelevantes, é, em parte, responsável pelo atraso no processo de análise do estudo e, consequentemente, de emissão da licença. Essa condição foi contornada no município de Itapemirim por meio da implantação do Sistema de Informação e Diagnóstico (SID), que aumentou a objetividade na obtenção de informações sobre os empreendimentos licenciados (ROZA, 2015).

A falta de equipamentos técnicos, sobretudo veículos para a realização de vistorias, foi apontada pelos entrevistados PITEP4 e PIAGP. Essa condição não é exclusiva dos quatro municípios pesquisados. Valinhas (2009) afirma que apesar de emitir licenças ambientais, muitos órgãos não possuem estrutura física e equipamentos para a realização das atividades. Guilherme e Henkes (2013) ainda assinalam a falta de organização do ambiente de trabalho e a baixa velocidade da Internet como entraves, visto que, no município fluminense de Itaguaí, os funcionários acessam o sistema do Instituto Estadual do Ambiente (Inea) do Rio de Janeiro para a realização de vários procedimentos. De acordo com Marconi (2012), o estado do Paraná adiou o processo de transferência do licenciamento ambiental de atividades de impacto local para o município de Londrina diante da falta de capacidade institucional (recursos humanos, financeiros e capacitação de pessoal) da prefeitura.

Por fim, a legislação ambiental municipal foi destacada como um problema nas capitais estudadas. Em Teresina, o entrevistado PITEP3 salientou que a legislação ambiental municipal é falha, principalmente por não existir uma lei que determine as diretrizes para o licenciamento ambiental, sendo que este só aparece na política municipal de meio ambiente. Já em Belo Horizonte, o entrevistado MGBHP1 destacou que existem conflitos entre a lei urbanística e ambiental. O entrevistado MGBHP4 ainda destaca a subjetividade das leis ambientais:

\begin{abstract}
As maiores dificuldades advindas nesses processos são os entendimentos subjetivos sobre essas questões. Numa mesma Secretaria de Meio Ambiente podem surgir conflitos de entendimentos e posições antagônicas. A legislação, especialmente no caso de Áreas de Preservação Permanente (APP), dá margem a interpretações caso a caso (ENTREVISTADO MGBHP4).
\end{abstract}

\title{
3.2.3 PONTOS FORTES DO LICENCIAMENTO AMBIENTAL MUNICIPAL
}

$\mathrm{Na}$ terceira questão, os entrevistados ressaltaram questões que podem afetar positivamente o licenciamento ambiental no município, reunidos em quatro categorias: i) Equipe multidisciplinar qualificada; ii) Proximidade do órgão ambiental; iii) Agilidade e desburocratização; iv) Arrecadação do município; v) Conselho Municipal de Meio Ambiente; e vi) Legislação ambiental.

A existência de uma equipe multidisciplinar qualificada e motivada no órgão ambiental é um dos aspectos positivos apontados pelos entrevistados MGBHP1 e MGBHP2, em Belo Horizonte, e pelo entrevistado MGBTP1, em Betim. No órgão ambiental de Teresina, apesar da baixa capacidade técnica relatada por todos os entrevistados, PITEP4 apontou, como ponto forte, a existência de profissionais que tentam conduzir o processo de licenciamento de forma ética. Esses resultados sugerem opiniões conflitantes em relação à capacidade técnica da equipe do órgão licenciador do município de Teresina.

Em Água Branca, apesar da ausência de fiscais declarada pelo entrevistado PIAGP, a Secretaria Municipal de Meio Ambiente realiza parcerias com outros departamentos, como a vigilância sanitária, para a realização de vistorias e autuações. Essa mesma experiência foi apontada por Neves (2013), que descreveu situação semelhante nos municípios do interior do Pará, os quais buscavam superar suas fragilidades por meio de parcerias com outros órgãos.

A proximidade do órgão com os problemas ambientais locais é um dos principais argumentos a favor da municipalização do licenciamento ambiental, de maneira que facilita e incentiva uma maior participação da sociedade na problemática ambiental local (ARRUDA JÚNIOR; ANDRADE, 2015; ASSETTO et al., 2003; 
ÁVILA; MALHEIROS, 2012; REIS, 2012). Esse ponto foi destacado apenas pelos entrevistados PITEP1 e PITEP2. Segundo o entrevistado PITEP2, a descentralização "intensifica a fiscalização dentro do próprio município" e proporciona "maior agilidade na resolutividade de denúncias contra o meio ambiente". O entrevistado PITEP1 afirma que a proximidade do órgão pode aumentar as cobranças em cima dos empreendimentos.

Nesse mesmo sentido, o entrevistado MGBHP4 afirma:

O município conhece melhor os problemas locais que o Estado. É possível colocar uma lente de aumento e tratar com mais critério os licenciamentos, pois a gama de problemas é menor e mais específica se comparada aos problemas enfrentados pelo Estado (ENTREVISTADO MGBHP4).

O entrevistado MGBTP2 citou a frequência de reuniões do Conselho de Meio Ambiente, a cada 15 dias, como um ponto forte do licenciamento em Betim. No entanto, nenhum dos entrevistados citou a proximidade da população e o aumento da participação social como um resultado positivo da municipalização.

Todos os entrevistados de Betim consideraram que a agilidade na análise dos processos é um aspecto positivo encontrado no licenciamento ambiental no município (MGBTP1, MGBTP2 e MGBTP3). O entrevistado MGBTP2 ressalta que essa celeridade está condicionada à apresentação de todos os documentos necessários por parte do empreendedor. O mesmo entrevistado ainda compara o processo com o órgão estadual: "Considerando que a competência se limita ao município de Betim, diferente do órgão ambiental [estadual], que atende vários municípios, a análise e deliberação é mais rápida" (ENTREVISTADO MGBTP2).

Por outro lado, o entrevistado PITEP3 definiu, como ponto forte, a existência de procedimentos técnicos bem definidos para o licenciamento de atividades específicas no município de Teresina, como, por exemplo, estabelecimentos de serviços de saúde (hospitais, clínicas médicas, etc.), uma das poucas tipologias que possuem Termo de Referência específico e equipe qualificada para análise dos processos.

\subsubsection{RECOMENDACÕ̃ES ÀS PREFEITURAS}

Na quarta e última questão foi solicitado que os entrevistados fizessem recomendações para as prefeituras que pretendem implantar o licenciamento ambiental, agrupadas em quatro categorias: i) Contratação, capacitação e remuneração de servidores; ii) Estruturação do órgão ambiental; iii) Planejamento e reconhecimento do território; iv) Fortalecimento da legislação ambiental local.

A formação de corpo técnico qualificado e motivado foi apontada por sete dos dez entrevistados. Os entrevistados MGBTP3, PITEP1 e PIAGP ressaltaram a importância da realização de concurso público para a contratação de efetivo multidisciplinar que possa suprir a demanda do órgão. $O$ entrevistado PITEP3 cita ainda a possibilidade de realização de convênios com instituições de ensino superior e conselhos de classe para suprir demandas mais imediatas e mais específicas, evitando a transferência de funcionários de outras secretarias que não possuam qualificação necessária para atuar como analistas ambientais. $O$ entrevistado MGBHP4 sugeriu:

Contratem técnicos para avaliação dos diversos temas envolvidos nos licenciamentos: avaliação do meio físico, biótico e antrópico. Os licenciamentos envolvem equipes multidisciplinares e as secretarias devem estar aparelhadas (ENTREVISTADO MGBHP4).

Os entrevistados MGBTP3 e PIAGP destacam a capacitação contínua dos servidores. De acordo com o entrevistado PITEP2, esses servidores muitas vezes desconhecem a legislação ambiental. 0 entrevistado PITEP2 destaca a importância de formar uma equipe que trabalhe efetivamente sem se corromper. Para que isso ocorra, segundo o entrevistado MGBTP3, esses servidores devem receber um salário compatível com o nível de responsabilidade e trabalho que desenvolvem. Essa mesma recomendação foi dada por Guilherme e Henkes (2013) ao órgão ambiental de Itaguaí.

Além de investir nos recursos humanos, a prefeitura que deseja implantar o licenciamento ambiental deve fornecer estrutura de trabalho, como computadores com softwares que facilitem as tarefas 
dentro do órgão e veículos para a realização de vistorias (MGBTP3, PITEP1 e PITEP2). O investimento em infraestrutura também foi apontado por Chiesa (2009), Guilherme e Henkes (2013) e Valinhas (2009).

Alguns entrevistados apontaram a importância do município possuir legislação ambiental própria. 0 entrevistado MGBHP1 destacou a importância de se estabelecerem normas e procedimentos para que as diferentes atividades licenciadas pelo município sejam exercidas dentro dos parâmetros legais definidos. $O$ entrevistado MGBTP2 sugeriu a elaboração de Plano Diretor, enquanto que o entrevistado PITEP3 destacou a elaboração de uma política municipal de meio ambiente. O entrevistado PIAGP destaca a urgência da padronização do licenciamento devido à existência de diferentes procedimentos aplicados para a análise de um mesmo tipo de atividade:

Estabeleçam critérios claros para os licenciamentos, criando gerência de planejamento; deliberações normativas que vão nortear os técnicos envolvidos; realização de seminários para nivelamento de informações entre os técnicos (ENTREVISTADO MGBHP4).

Para o entrevistado MGBHP1, o gestor deverá ter um bom conhecimento do território onde vai atuar e realizar o planejamento do uso e ocupação do solo. Além disso, o entrevistado MGBHP2 definiu: estabelecer objetivos e metas de melhorias para o município, além de manter as questões políticas em segundo plano, prevalecendo os aspectos técnicos:

Estabeleçam parcerias eficientes de comunicação com os prestadores de serviços públicos de água, esgotamento sanitário, drenagem, lixo, trânsito, remoção e reassentamento, outros porventura existentes, tais como fornecedores de gás (ENTREVISTADO MGBHP4).

Os entrevistados MGBTP2 e PITEP3 recomendaram a implantação de Conselho Municipal de Meio Ambiente, enquanto que o entrevistado MGBTP1 apontou a importância de manter a frequência das reuniões. A participação da população no processo de licenciamento foi apontada pelo entrevistado PIAGP, que ressaltou a relevância de se trabalhar a educação ambiental na comunidade, destacando a importância da comunidade compreender que o processo de licenciamento não é uma punição, mas sim uma forma de preservar a qualidade ambiental local.

\section{CONSIDERAÇÕES FINAIS}

Apesar do crescente interesse pela descentralização e municipalização do licenciamento ambiental, poucos estudos científicos com revisão de pares avaliaram esse fenômeno, sobretudo no Nordeste. Esta pesquisa avaliou comparativamente experiências de municipalização do licenciamento ambiental em dois municípios do Piauí e dois municípios de Minas Gerais, de modo a entender quais fatores têm favorecido ou dificultado o licenciamento no âmbito local.

Foram identificadas importantes diferenças institucionais e regulatórias entre municípios do Sudeste e Nordeste. As raízes das diferenças, todavia, não ficaram claras. O município de Água Branca (PI), município com menor população, IDH e PIB per capita, evidenciou a maior limitação institucional e procedimental para a condução do licenciamento ambiental, um fato que corrobora a importância de se desenvolver mecanismos de fortalecimento institucional para municípios com condições socioeconômicas desfavoráveis. O município de Teresina (PI), apesar de ser uma capital, apresentou entraves semelhantes aos apontados pelo entrevistado de Água Branca. O quantitativo de funcionários é formado por servidores comissionados ou emprestados de outras secretarias, além disso, a estimativa de salário mensal bruto foi inferior à dos demais municípios estudados.

O município de Betim (MG), apesar de ser um município interiorano, faz parte da região metropolitana de Belo Horizonte (MG) e apresenta um sistema de licenciamento muito similar ao da capital do estado. Sua secretaria dispõe de um quantitativo relativamente alto de corpo técnico, bem como de sistemas de informação e rotinas procedimentais compatíveis com a do licenciamento estadual. Vale ressaltar que o município de Betim se apresenta em um contexto socioeconômico bastante distinto de Água Branca, visto que o IDH é alto e o PIB per capita supera o da capital mineira, Belo Horizonte. Esse resultado sugere que o fato de ser "interiorano" não determina a maturidade do licenciamento municipal. 
Os resultados desta pesquisa, de maneira geral, sugerem que a capacidade institucional do órgão ambiental municipal não é definida pelo fato de ser da capital ou do interior, mas sim pelo nível de desenvolvimento econômico e institucional do órgão. Problemas ambientais tendem a ser mais complexos em regiões mais desenvolvidas, populosas e industrializadas, direcionando a administração municipal a se estruturar de forma compatível com a realidade local. Por meio das informações relacionadas à dimensão regulatória, constatou-se que os municípios piauienses tiveram regulação do licenciamento ambiental mais tardia em relação aos municípios mineiros. A dimensão institucional, por sua vez, sugeriu maior capacidade dos órgãos ambientais de Belo Horizonte e Betim, refletida no número de servidores, composição e formação da equipe técnica e maiores salários.

A análise da percepção dos atores envolvidos no licenciamento ambiental levou a uma compreensão mais profunda dos fatores que favorecem positiva e negativamente a efetividade do licenciamento nos municípios estudados. De maneira geral, esses fatores estavam alinhados com os resultados de estudos passados sobre o licenciamento ambiental municipal, que destacaram fatores relacionados a pessoal, infraestrutura e regulação como críticos para a efetividade do sistema.

Como argumenta Gibson (2006), o licenciamento é um instrumento de promoção de desenvolvimento sustentável no território. Esta pesquisa procurou entender como esse instrumento está sendo regulado e institucionalizado em diferentes municípios, mas sem tratar dos seus desdobramentos socioambientais. Nesse sentido, espera-se que estudos futuros avancem no entendimento dos efeitos da municipalização para a qualidade do meio ambiente e para o bem-estar das populações locais.

\section{AGRADECIMENTOS}

Os autores agradecem à Fundação de Amparo à Pesquisa do Estado de Minas Gerais (FAPEMIG) pelo apoio financeiro concedido, através do Projeto APQ-01640-14, para as pesquisas que resultaram neste artigo. Os autores também agradecem aos entrevistados e a todas instituições que, de alguma forma, auxiliaram na coleta de dados.

\section{REFERÊNCIAS}

ARRUDA JÚNIOR, P.; ANDRADE, R. C. Licenciamento Ambiental: aspectos gerais sobre o instituto e a (in)eficaz Lei Complementar 140/2011. In: Licenciamento Ambiental: herói, vilão ou vítima. Belo Horizonte: Arraes Editores, 2015.

ASSETTO, V. J.; HAJBA, E.; MUMME, S. P. Democratization, decentralization and local environmental policy capacity: Hungary and Mexico. The Social Science Journal, v. 40, n. 2, p. 249-268, 2003.

ÁVILA, R. D.; MALHEIROS, T. F. O sistema municipal de meio ambiente no Brasil: avanços e desafios. Saúde e Sociedade, v. 21, n. suppl. 3, p. 33-47, 2012.

BLAZINA, A. G.; LIPP-NISSINEN, K. H. Contribuição ao conhecimento da evolução do licenciamento ambiental municipal no Rio Grande do Sul (RS). Fepam em Revista, v. 3, n. 2, p. 12-25. Porto Alegre, 2010.

BRANDT, F. et al. O desafio do Licenciamento Ambiental no município de Roca Sales, Rio Grande do Sul, Brasil. Revista de Ciências Ambientais, v. 7, n. 2, p. 73-86, 2014.

BRASIL. Lei Complementar n. 140, de 8 de dezembro de 2011. Fixa normas, nos termos dos incisos III, VI e VII do caput e do parágrafo único do art. 23 da Constituição Federal, para a cooperação entre a União, os Estados, o Distrito Federal e os Municípios nas ações administrativas decorrentes do exercício da competência comum relativas à proteção das paisagens naturais notáveis, à proteção do meio ambiente, ao combate à poluição em qualquer de suas formas e à preservação das florestas, da fauna e da flora; e altera a Lei n. 6.938, de 31 de agosto de 1981. Diário Oficial da União, Brasília, 9 dez. 2011. 
BRASIL. Lei n. 6.938, de 31 de agosto de 1981. Dispõe sobre a Política Nacional do Meio Ambiente, seus fins e mecanismos de formulação e aplicação, e dá outras providências. Diário Oficial da União, Brasília, 2 set. 1981.

CHIESA, M. Gestão Ambiental: entraves e perspectivas para a municipalização no estado do Espírito Santo. In: CONGRESSO CONSAD DE GESTÃO PÚBLICA, 2, 2008, Brasília. Anais... Brasília: UNB, 2008.

CONSELHO NACIONAL DO MEIO AMBIENTE - CONAMA. Resolução no 237, de 19 de dezembro de 1997. Altera a Resolução no $1 / 86$ (revoga os art. 3o e 7으). Dispõe sobre a revisão e complementação dos procedimentos e critérios utilizados para o licenciamento ambiental. Disponível em <http://www. mma.gov.br/port/conama/res/res97/res23797.html>. Acesso em: 04 dez. 2015.

CONSELHO NACIONAL DO MEIO AMBIENTE - CONAMA. Resolução no 01, de 23 de janeiro de 1986. Dispõe sobre critérios básicos e diretrizes gerais para o Relatório de Impacto Ambiental - Rima. Disponível em: <http://www.mma.gov.br/port/conama/legiabre.cfm?codlegi=23>. Acesso em: 04 dez. 2015.

CORRÊA, S. de A. Descentralização da gestão ambiental no estado do Pará e suas implicações no licenciamento ambiental (1988-2010). 2011. 147 f. Dissertação (Mestrado em Desenvolvimento Sustentável) - Programa de Pós-graduação em Desenvolvimento Sustentável do Trópico Úmido, Núcleo de Autos Estudos Amazônicos, Universidade Federal do Pará (UFPA), Belém.

CRESWELL, J. W. Projeto de pesquisa: métodos qualitativo, quantitativo e misto. 3. ed. Porto Alegre: Artmed/Bookman, 2010.

FARIAS, P. J. L. Competência comum e o federalismo cooperativo na subsidiariedade do licenciamento ambiental: avanços da Lei Complementar 140/2012 na proteção do meio ambiente. Revista de Informação Legislativa, v. 51, n. 203, p. 39-51, 2014.

FOLLESDAL, A. Survey Article: subsidiarity. The Journal of Political Philosophy, v. 6, n. 2, p. 190-218, 1998.

FONSECA, A.; RESENDE, L. Boas práticas de transparência, informatização e comunicação social no licenciamento ambiental brasileiro: uma análise comparada dos websites dos órgãos licenciadores estaduais. Engenharia Sanitária e Ambiental, v. 21, n. 2, p. 295-306, 2016.

FONSECA, A.; SÁNCHEZ, L. E.; RIBEIRO, J. C. J. Reforming EIA systems: a critical review of proposals in Brazil. Environmental Impact Assessment Review, v. 62, p. 90-97, 2017.

GIBSON, R. B. Beyond the Pillars: Sustainability Assessment as a Framework for Effective Integration of Social, Economic, and Ecological Considerations in Significant Decision-making. Journal of Environmental Assessment Policy and Management, v. 8, n. 3, p. 259-280, 2006.

GUERRA, S. C. S. Competência ambiental à luz da Lei Complementar no 140/2011. Nomos, Fortaleza, v. 32, p. 125-140, 2012

GUILHERME, F. C.; HENKES, J. A. A execução do licenciamento ambiental no município de Itaguaí - RJ. Revista de Gestão e Sustentabilidade Ambiental, v.1, n. 2, p. 82-146, 2013.

INSTITUTO BRASILEIRO DE GEOGRAFIA E ESTATÍSTICA. Perfil dos Municípios Brasileiros: 2015. Brasília: Instituto Brasileiro de Geografia e Estatística (IBGE), 2016.

MARSHALL, G. R. Nesting, Subsidiarity, and Community-based Environmental Governance beyond the Local Scale. International Journal of the Commons, v. 2, n. 1, p. 75-97, 2007.

NEVES, M. S. C. N. Diagnóstico da gestão ambiental municipal do estado do Pará. Programa Municípios Verdes, Imazon e Clua. Belém, 2013. 
OLIVEIRA, F. S. D. et al. Licenciamento ambiental simplificado na região Sudeste Brasileira: conceitos, procedimentos e implicações. Desenvolvimento e Meio Ambiente, v. 38, p. 461-479, 2016.

REIS, M. M. Licenciamento Ambiental municipal: instrumento garantidor da realização do desenvolvimento sustentável. 2012. 84 f. Dissertação (Mestrado em Direito) - Universidade de Caxias do Sul (UCS), Caxias do Sul.

RIBOT, J. C. Democratic Decentralization of Natural Resources: institutionalizing popular participation. World Resources Institute (WRI), 2002.

ROZA, J. P. Aperfeiçoamento na análise de processos de Licenciamento Ambiental em Itapemirim. In: CONGRESSO BRASILEIRO DE GESTÃO AMBIENTAL, 6, 2015, Porto Alegre. Anais... Porto Alegre: Centro Metodista IPA, 2016.

SANCHEZ, L. H. Development of Environmental Impact Assessment in Brazil. UVP Report, v.27, p. 1932013.

SOUZA, M. L. C. Municipalização da gestão ambiental: análise comparativa do processo de descentralização nos estados da Bahia, Minas Gerais e Rio Grande do Sul. 2003. 187 f. Dissertação (Mestrado em Desenvolvimento Sustentável) - Centro de Desenvolvimento Sustentável, Universidade de Brasília (UNB), Brasília.

VALINHAS, M. M. O Município de Macaé-RJ face ao processo de descentralização da fiscalização e do licenciamento ambiental no estado do Rio de Janeiro. Boletim do Observatório Ambiental Alberto Ribeiro Lamego, Campos dos Goytacazes/RJ, v. 3, n. 1, p. 11-28, jan./jun. 2009. 